\title{
The Coastline Extraction for Fujian Province Based on Long Time Series of Remote Sensing Image
}

\author{
Liangzhao Lin, Zengdi Pan \\ School of Ocean and Earth Science, Tongji University \\ Shanghai, China \\ lliangzhao@163.com
}

\begin{abstract}
In order to study the impact that land reclamation had on coastline of Fujian Province, three phases of Landsat TM/ETM+ image, spanning 15 years, were used to monitor the coastline change. The entire coastline was extracted from preprocessed Landsat TM/ETM+ images based on edge detection operator-Canny. We also improved the computational efficiency of image analysis by developing an image blocking algorithm with the IDL embedded in ENVI software. The length of the coastline for each imagewas calculated through the spatial calculation function of GIS platform, which shows that the length of Fujian coastline ranges from $3167.4 \mathrm{~km}$ to $3218.2 \mathrm{~km}$, and to $3304.7 \mathrm{~km}$. Our results also indicate that the land reclamation in Fujian Province has caused the coastal lineto become shorter year by year.
\end{abstract}

Index Terms - coastline extraction, edge detection, canny, IDL\&ENVI, GIS.

\section{INTRODUCTION}

As the third largest aquaculture province in China, Fujian has a long meandering coastline with a total length of 3324 kilometers, accounting for one-sixth of the national coastline. Fujian coastline is ranked the second longestand the first tortuous one in China. However, in recent years, with the boom of large-scale coastal industries including harbor, shipbuilding, electricity and machinery, there has been an increasing land demand in Fujian province which in fact cannot be met by the natural supply. Therefore, the reclamation has been an important supplement for the necessary land useforlocal development. Although the previousreclamation has brought local people numerous socioeconomic benefits, it also dramatically transformed the Fujian coastal areas in terms of the shape of the gulf and the length of the coastline $[1,2]$.

Due to the advantages in real-time, large-scale and continuous monitoring which cannot be compared by the conventional methods, ocean remote sensing has great potential in efficientlymonitoring the change of coast line from a spatial-temporal perspective.A number of nationwide large-scale regular surveys have been conducted in China since the middle 1980s [3]. As the computer technology continues to evolve, the level of automatic interpretation of coastline change has greatly improved. Thishas gradually replaced the traditional visual interpretation and become the mainstream of interpretation techniques.F. Lan-di performed wavelet transformation to obtain the data of coastline as well as the edge image of Yellow River Delta [4];Z. Xiao-ge used multi-temporal

\author{
Kang Xiao, Na Ye \\ East Sea Information Center, State Oceanic Administration \\ Shanghai, China \\ xkys822111@gmail.com
}

Landsat satellite remote sensing images to monitor the changes of the Pearl River estuary shoreline based on the neural network classification methods. The growth of the land area was calculated. An effective means of monitoring long-term, real-time Pearl River Estuary coastal change with remote sensing was proposed in their research [5]; H. Zhen integrated the Landsat passive reflection infrared data, thermal infrared data and synthetic aperture radar (ERS-2 SAR) active microwave data and other information sources to extract the shoreline information of Yangtze River Estuary where there are high suspended sediment concentration using the Laplace-Gauss, Roberts and Soble algorithms respectively. It is concluded that the best is Soble algorithm, followed by Roberts algorithm and Laplace-Gauss algorithm, and it also pointed out that high levels of suspended sediment has considerable effect on the extraction of sideline information [6];Mr. Xiao-fenghad the Liaoning Province Dalian, Yingkou area seacoast as the study area, proposing the interpretation method about the coastline on the basis of different seacoast types of landform characteristics from the satellite imagery.The special pretreatment was carried on with the aid of the digital image processing technology to the different types of seacoast imagery, using IDL to realize the Canny operator, median filter and Erosion operator. It identified that the satellite imagery in coastline automatic withdrawing can providea method for computing slope to unify the tide level and the satellite imagery [7].

Based on the long-time multi-temporalLandsat TM/ETM+ data,our study revealed the overall spatial-temporal variation of the coastlines, and discussed the effects of reclamation on thecoast line length.

\section{DATA SOURCES AND METHODOLOGY}

\section{A. Data Sources}

Three phases of Landsat TM/ETM+ image (1994/2002/2009), spanning 15years, were applied to monitor the coastline of Fujian. As the coastline is too long for image mosaic, it is not a good way to cover theentire Fujian coastline for the same phase. Our studyused remote sensing image in similar temporal periodsto compose one image which contains the entire coastline. All Landsat TM / ETM + images were downloaded from International Scientific Data Service Platform [8] and Earth Observation Data Sharing Plan Platform[9] corresponding to the path/row number of the satellite passing through Fujian sea areas. The specific date,path/row number are listed in the following. 
TABLE I. THE SPECIFICATION OF LANDSAT TM/ETM+ IMAGE

\begin{tabular}{|c|c|c|c|c|}
\hline \multirow{2}{*}{ Phase } & $\begin{array}{c}\text { Landsat } \\
\text { Satellite }\end{array}$ & Date & Path & Row \\
\hline \multirow{3}{*}{1994} & \multirow{3}{*}{2002} & $1994-5-12$ & 119 & $41 / 42 / 43 / 44$ \\
\cline { 3 - 5 } & \multirow{3}{*}{ Landsat 5 } & $1995-9-11$ & 120 & 44 \\
\cline { 3 - 5 } & & $1995-9-13$ & 118 & 41 \\
\hline \multirow{3}{*}{2009} & \multirow{3}{*}{ Landsat 7 } & $2001-11-22$ & 120 & 44 \\
\cline { 3 - 5 } & & $2002-2-12$ & 118 & 41 \\
\cline { 3 - 5 } & & $2002-2-26$ & 120 & 43 \\
\hline & & $2002-3-7$ & 119 & $41 / 42 / 43$ \\
\cline { 3 - 5 } & & $2009-5-12$ & 120 & 44 \\
\cline { 3 - 5 } & & $2009-6-6$ & 119 & $41 / 42 / 43$ \\
\cline { 3 - 5 } & & $2009-10-19$ & 120 & 43 \\
\hline
\end{tabular}

\section{B. Methodology}

The general idea of this paper is to integrate automatic interpretation with visual interpretation. We selected Landsat $\mathrm{TM} / \mathrm{ETM}+$ image as a source of information. After a series of preprocessing on the original Landsat TM/ETM+ image, based on the sensitivity of the distinction between the land and seacharacteristics in theinfrared band, the whole coastlinewasextracted using the edge detection operators-Cannyandimage block processing technologyin ENVI platform.In addition, we used GIS spatial analysis to calculate the length of Fujian coast line by grid-vector, coordinates registration, and visual interpretationfrom thevectorized coastline and true color composite image. The specific processis shown in Fig. 1.

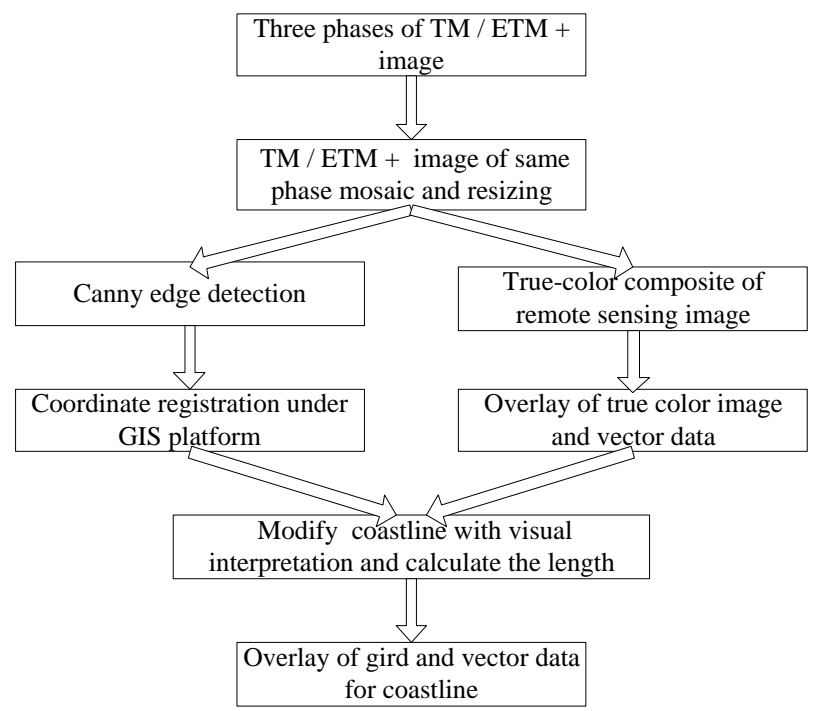

Fig.1. Flow chart of technical routes of Fujian coastline extraction

\section{DATA PREPROCESSING}

As Landsat TM / ETM + imagesdownloaded have been done radiometrically and geometrically corrected, we need to unify all phases of Landsat TM/ ETM + data and vector data in the same projection coordinate system (UTM projection, WGS-84 coordinate system).

Due to the wide range of Fujian Sea and the limited regions Landsat TM / ETM + images cover, it is necessary tomosaicthe different scenes of our Landsat TM / ETM + imagesin different paths and rows to an image which covers our whole study area. In this study,the mosaic of corresponding single-band was implemented respectively, eventually resulting in an composite imagefor the wholeFujian coastal area in multiple bands.

According to thecrossing latitude and longitudeinformation $\left(23^{\circ} 30^{\prime}-28^{\circ} 22^{\prime} \mathrm{N}, 115^{\circ} 50^{\prime}-120^{\circ} 40^{\prime} \mathrm{E}\right)$ of Fujian Province, three phases of Landsat TM / ETM + images were resized by ENVI software module, forming the image covering the research area.

\section{COASTLINE EXTRACTION}

Based on the actual situation of Fujianprovince's long and winding coastline and containing about half of bedrock coasts, our study only focused on the investigation of the overall dynamic changesof Fujian's coastline in a long-time period.The impact of different tidal level and landform types on the coastline extraction was not considered because of the resolution limitation of our research data.

\section{A. Canny edge detection operator}

The extraction ofcoastline can be conducted by edge detection technique for remote sensing imagery analysis. Since the edge of the image corresponding to the discontinuity of the image gray value, the edge detection algorithm can be used to determine whether the pixel is in the boundary or notby examining each pixel and its immediate neighbor pixel. This process can followprinciple that the gray value of pixels on the boundary has relatively large changes[10].

In this paper, on the IDL platform, the edge detection operators Soble, Prewitt, Roberts, Marr and Canny were achievedby programming and then it was implemented on the intercepted image of Fujian sea,as shown in Fig.2. Canny is considered as the best edge detection operator to extract the clearest image edge, with excellent continuity and no breakpointsin principle. Sea and land boundaries in the satellite images are ladder-type edge that is transformed from land to sea water when the gray values of the image will change. This feature was in line with the Canny operator edge positioning accuracy.Thesame edge has the extraction limit conditions of the low number of responses, so Canny operator able to achieve good test results.

\section{B. Image block processing}

In this paper, the three phases of Landsat TM/ETM+ images are from image mosaic of six similar periods. As the mosaic of tremendous data requires a long time, it is often difficult to deal with the process. Taking TM images in 2009 for example, the quality of mosaic image is $16820 \times 17436$ (byte), causing the program available. This is because general procedure for handling such an image is often out of memory. Therefore, image technology wasapplied to Canny edge detection for the entire image extraction combining IDL and ENVI. 

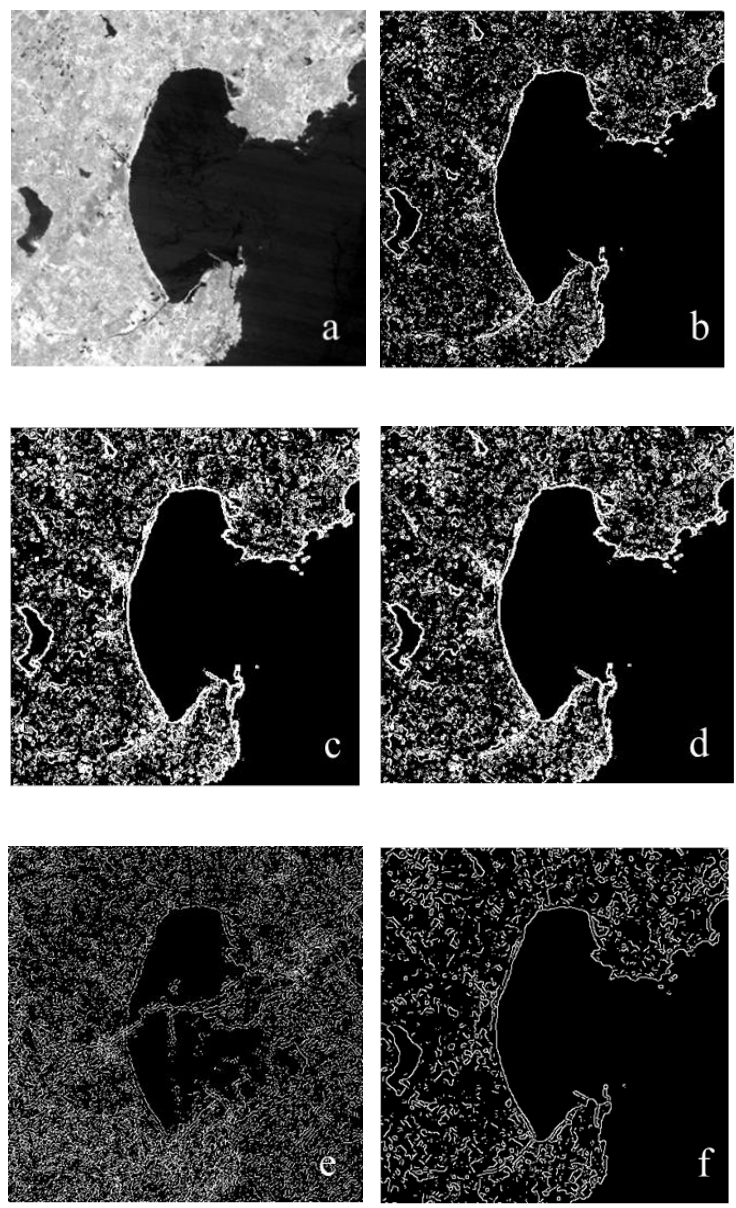

Fig.2 The comparison of coastline extraction near Jinjiang by five algorithms

a. Original b.Robertsc.Prewitt d.Soblee.Marr f.Canny

For ENVI block processing, the input data wasdivided into units of the same size by way of space, in order to ensure that all the sizes of the image can be processed.Alsothe size of a spatial block is nlines $\times$ sample.

In this study, the massive three phasesof mosaic Landsat TM/ETM+ imagewerehandled byblock processing respectively.Afterwards, the processing results werestored in the filefollowing the edge detection by Canny operator, forming the result of Canny- operator edge detection.

\section{The results of coastline extraction and analysis}

After automatic detection and visual interpretation, the overlay image of remote sensing and vector data for Fujian Sea coastlinewasultimately obtained (Fig. 3).According to findings of Fujian coastal zones and shoals resources in the comprehensive survey from the early to the middle 1980s (about six years), Fujian has coastline length of $3351 \mathrm{~km}[2]$; there is also a verifiable coastline length data of Fujian Province $-3324 \mathrm{~km}$ that has beenhabitually adopted from 1990[11].Inthis paper, the measured length of coastline extraction using Landsat TM/ETM + image is $3304.7 \mathrm{~km}$, as well as $3218.2 \mathrm{~km}$ for 2002 and $3167.4 \mathrm{~km}$ for 2009 . Therefore,coastline length extracted from LandsatTM/ETM+ data are consistent with the previous results, meeting the requirements of accuracy. As can be seen from the calculation results, Fujian province's coastline tends to be shorter and shorteroverall.
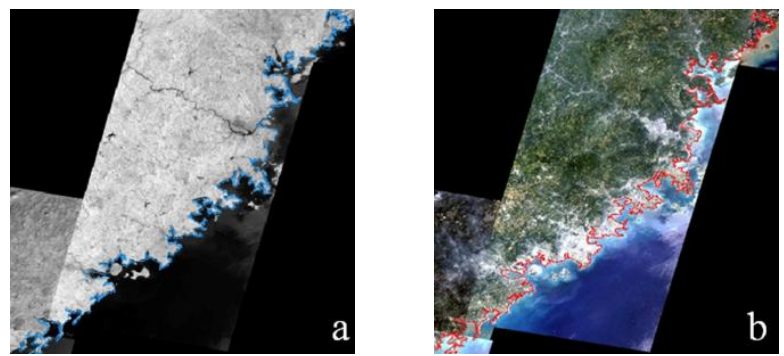

Fig.3. Overlying of coastline extraction and remote sensing image of Fujian Province a. 4th bandb. true color

According to the reclamation situation of Fuqing Bay and Xinghua Bay mentioned in previously published papers, the present studymade use of 10 Landsat TM / ETM + images of Fujian Province ranging from 2000 to 2009 to extract coastline for two gulfs where greater reclamation occurred(coastline extraction results of 2008shown in Figure 4).The length was calculated and statistics were performed on ArcGIS platformwith results shownin Figure 5.
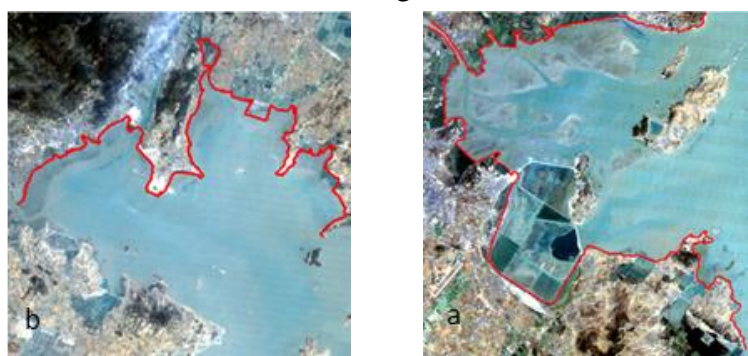

Fig.4.Overlying of coastline extraction and remote sensing image of Fujian Province's localregion

a. Fuqing Bay b. Xinghua Bay

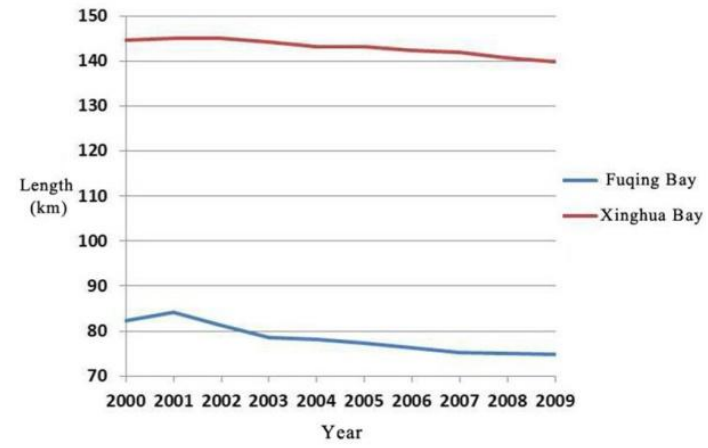

Fig.5.Length statistics of extracted coastline of Fujian Fuqing Bay and Xinghua Bay from 2000 to 2009

The Fuqing Bay had performed a total of 15 reclamation projects, reachingan area of $98.32 \mathrm{~km}^{2}$. A large area of the reclamationhas causedthe consequence of deteriorated hydrodynamic conditions significantly, weakened the 
self-purification capacity of seawater, and causedthe aggravated bay siltation, the rapid accumulation of pollutants and the frequent occurrence of red tides [12]. The reclamation of Xinghua Bay is more intensive, distributingin different spatial scalesalmost along the entire coastline. Thishas reached a total area of $122.08 \mathrm{~km}^{2}$ since $1950 \mathrm{~s}$, accounting for about $19.62 \%$ of the entire Gulf $[13,14]$.

As can be seen from Figure 5, the coastline length of Fuqing Bay and Xinghua Bay showsa gradually decreasing trendfor 10 years. In the meantime,the variations of Xinghua Bay coastline is relatively small to Fuqing Bay,which is due to the fact thatXinghua Bay belongs to bedrock Gulf with deposition structure.

In summary, the reclamation and utilization of land has directly changed the coastline, resulting in terms of length and shape in part of the Gulf shoreline from natural evolution pattern to artificial damming. Meanwhile, in order to save the cost of reclamation, natural shoreline has been taken straightartificially, causing a shorter trend of the Fujian Province coastline.

\section{ACKNOWLEDGMENT}

This research was partially supported by open research fund of National Marine Environment Monitoring Center. The authors gratefully acknowledge the comments from Dr. HuipingXu.

\section{REFERENCES}

[1] S. Mei-xian, and Z. Wei,"Study on coastline remote sensing survey and application in Fujian Province," Journal of Oceanography in Taiwan Strait, vol. 23, pp. 213-218, May 2004.

[2] L.Jing-liang, "The comprehensive survey report of Fujian coastal zones and shoals resources", Beijing: Ocean Press, pp.3-4,1990.

[3] Y. Xiao-mei, L.Rong-qin, and D. Yun-yan, "Technical foundation research on high resolution remote sensing system of

China's Coastal Zone," ActaOceanologicaSinica, vol. 23, pp.

109-118, 2004.
[4] F. Landi, S. Xiao-gong, and X. Ke-hui, "Edge detection of coastline based on wavelet transform method," Journal of Ocean University of Qingdao, vol. 32, pp. 777-781, September 2002.

[5] M. Xiao-feng, Z. Dong-zhi, X. Xiao-gang, Z. Feng-shou, W. Shi-yong, and Y. Fan, "Means of withdrawing coastline by remote sensing, " Marine Environmental Science, vol. 26, pp. 185-189, Apirl 2007.

[6] H. Zhen, and J. Ya-qiu, "The extraction of muddy tidal flats of the Yangtze Delta water sideline based on spaceborne infrared and microwave multi-source remote sensing data," Progress In Natural Science, vol. 15, pp. 1000-1006, August 2005.

[7] Z. Xiao-ge, "Remote sensing monitoring of coastline changes in Pearl River Estuary," Marine Environmental Science, vol. 21, pp. 19-23, May 2002.

[8] International Scientific Data Service Platform: http://datamirror.csdb.cn/index.htm

[9] Earth Observation Data Sharing Plan Platform: http://ids.ceode.ac.cn

[10] Y.Hai-bing, L. Bing-bai, and C. Min-dong, "Progress of researches in coastline extraction based on RS technique,"Areal Research and Development, vol. 28, pp. 101-105, February2009.

[11] F Wei-guo, "Study on large-scale marine function zoning of Fujian Province, "Beijing: Ocean Press, pp. 10-11, 2002.

[12] X.Peng, C. Wei-qi, W.Xuan,and M.Hai-tao, "Cost-benefit analysis of sea reclamation planning projects in Fuqing Bay," Journal of Xiamen University(Natural Science), vol. 46, pp. 214-217, August 2007.

[13]M.Zhi-yuan, C. Bin, Y. Wei-wei, and C Jian-ning, " Impact of reclamation on wetland landscape ecology in Xinghua Bay," Journal of Oceanography in Taiwan Strait, vol. 28, pp. 169-176, May 2009.

[14] Y. Wei-wei, C.Bin, and Z.Luoping, "Cumulative effects of reclamation on ecosystem services of tidal flat wetland - acase in the Xinghua Bay, Fujian, China," Marine Science Bulletin, vol. 27, pp. 88-94, February 2008. 